Article

\title{
Determining the Effect of Extreme Weather Events on Human Participation in Recreation and Tourism: A Case Study of the Toronto Zoo
}

\author{
Micah J. Hewer \\ Department of Physical and Environmental Sciences, University of Toronto at Scarborough, Toronto, \\ ON M1C 1A4, Canada; micah.hewer@utoronto.ca
}

Received: 20 December 2019; Accepted: 8 January 2020; Published: 15 January 2020

\begin{abstract}
This study devises a novel approach for defining extreme weather events and assessing their effects on human participation in recreation and tourism, based on a case study of attendance at the Toronto Zoo (Toronto, ON, Canada). Daily zoo attendance data from 1999 to 2018 was obtained and analyzed in connection with daily weather data from local weather stations for the maximum temperature, minimum temperature, total precipitation, and maximum wind speed. The "climatic distance" method, used for evaluating representative weather stations for case studies in applied climatology, was employed to rank and select surrounding weather stations that most accurately captured daily weather observations recorded at the Toronto Zoo from 1990 to 1992. Extreme weather events can be defined as lying in the outermost (most unusual) 10 percent of a place's history. Using this definition as the foundation, a percentile approach was developed to identify and assess the effects of extreme weather events across the following thresholds: the 99th percentile, the 95th percentile, and the 90th percentile, as well as less than the 1st percentile, less than the 5th percentile, and less than the 10th percentile. Additionally, revealed, theoretical, and binary thresholds were also assessed to verify their merit and determine their effects, and were compared to the extreme weather events defined by the percentiles approach. Overall, extreme daily weather events had statistically significant negative effects on zoo attendance in Toronto, apart from a few cases, such as the positive effect of usually warm daytime temperatures in the winter and usually cool nighttime temperatures in the summer. The most influential weather event across all seasons was extremely hot temperatures, which has important implications for climate change impact assessments.
\end{abstract}

Keywords: extreme weather events; tourism; recreation; participation; attendance; zoos and aquariums; climate change

\section{Introduction}

Tourism climatology is the study of the relationship between recreation and tourism and weather and climate [1-3]. Within the context of tourism climatology, zoos and aquariums have only recently been assessed regarding the weather sensitivity and climate change vulnerability of this type of recreation and tourism activity. The first study to look at the weather sensitivity of zoo attendance and assess climate change impacts was conducted by Aylen [4], who looked at Chester Zoo in the United Kingdom. Following this, Hewer and Gough [5] assessed the weather sensitivity of attendance at the Toronto Zoo in Canada, and then conducted a follow-up climate change impact assessment [6]. Both Aylen et al. [4] and Hewer and Gough [5] used a revealed preferences approach including multiple weather variables to create predictive weather sensitivity models. The next series of tourism climatology papers that focused on zoo attendance emerged from the United States, looking at thermal comfort for the Phoenix and Atlanta zoos [7], as well as the effect of synoptic weather systems for the 
Atlanta and Indianapolis zoos [8]. Another tourism climatology paper that examined zoo attendance was conducted by Hewer and Gough [9], which looked at the effect of seasonal climatic anomalies on attendance at the Toronto Zoo (Toronto, ON, Canada). Interestingly, both the Pekins and Debbage [7] and the Hewer and Gough [9] papers were published as part of the last special issue on tourism climatology in the MDPI journal Atmosphere. Most recently, Su and Lin [10] used a regression modeling approach similar to the work of Aylen et al. [4] and Hewer and Gough [5] to explore the weather sensitivity of zoo attendance at the Taipei Zoo in Taiwan. With only seven studies to date, zoos and aquariums have only begun to be studied in the context of tourism climatology. Despite findings suggesting that zoo and aquarium attendance is highly sensitive to weather and climate variability, other activities, such as visiting parks and protected areas, have received much more attention internationally within the tourism climatology literature [11-25].

Tourism climatology, which involves both the study of weather sensitivity and an assessment of climate change impacts, has been a growing field of study since the 1970s [26,27]. More recently, there have been calls for tourism climatology research that considers the effects of extreme weather events on human participation in recreation and tourism [28,29]; however, no known study to date has responded to these calls. Furthermore, there has been difficulty in the broader climatology and meteorology literature in terms of defining what constitutes an extreme weather event [30,31]. However, the United States National Centers for Environmental Information (NCEI), a division of the National Oceanic and Atmospheric Administration (NOAA) [32], has put forward the following definition: "extreme events are defined as lying in the outermost (most unusual) 10 percent of a place's history". The current study uses this definition as a foundation to devise a method for identifying extreme weather events from within the observational climate record (daily weather station data) and determining their effect on human participation in recreation and tourism, based on attendance data from the Toronto Zoo (1999 to 2018). This study will further contribute to understanding the relationship between the weather and climate and zoo attendance, while also establishing a novel method for addressing the need for tourism climatology research that studies the effect of extreme weather events on human participation in recreation and tourism.

Within the tourism climatology literature that has focused on attendance at zoos and aquariums, several non-climatic factors have been identified as influencing human participation. For example, weekends and holidays have been clearly shown to be associated with increased zoo attendance, both in Toronto [5,6] and in the United Kingdom [4]. Time, which is often a proxy for population growth and zoo expansion, has also been shown to result in increased zoo attendance in Toronto [5,6], the UK [4], and Taiwan [10]. Furthermore, previous studies in Toronto [9] and Taiwan [10] have also identified the positive effect of "animal stars" and other special attractions on zoo attendance, along with the negative effect of external events, such as disease epidemics, political instability, and competing events. It is therefore important to consider the potentially confounding effects of non-climatic factors in any tourism climatology study which examines the effects of weather and climate variability on human participation.

\section{Methods and Materials}

The Toronto Zoo in Ontario, Canada, was selected for this case study on tourism climatology. This was a convenient sample given that the researcher already possessed daily zoo attendance data from 1999 to 2015. However, after working out the methods for this study, the zoo was contacted once again, and an updated data set was retrieved, allowing the study to consider 20 years of the most recent daily zoo attendance data (1 January 1999 to 31 December 2018). The Toronto Zoo is also the largest zoo in Canada and the 5th largest zoo worldwide, making it an important zoo to study, while also enabling generalization of the results for other zoos in similar climates.

Daily weather data from 1999 to 2018 was retrieved from Environmental Canada's historical climate data archive. In this regard, local weather station data was used. However, there are numerous weather stations with applicable data in proximity to the zoo and weather data was also collected by 
an old Environment Canada weather station (Metro Zoo) that was in operation on the zoo property itself, from 1977 to 1992. Previous tourism climatology studies focusing on the Toronto Zoo have all used different weather stations for data acquisition. Initially, Hewer and Gough [5] established the weather sensitivity of zoo attendance (based on data from 1999 to 2014) and retrieved their climate data from the closest weather station, which is Buttonville Airport. Conversely, when Hewer and Gough [6] conducted a climate change impact assessment that required climate data from 1981 to 2014, again, the closest station with the necessary data was used (Richmond Hill weather station). However, when Hewer and Gough [9] were looking at the effect of seasonal climatic anomalies on zoo attendance, they introduced a new method for evaluating representative weather stations, referred to as "Climatic Distance". They concluded that the Toronto Pearson Airport best reproduced average monthly weather conditions at the Toronto zoo from 1977 to 1992, and thus used that station for their study.

This study will also employ the climatic distance method $[9,33]$, but will evaluate the ability of test stations to replicate daily weather data from 1990 to 1992 at the Toronto Zoo. This change was made because the current study considers daily weather extremes, not seasonal climatic anomalies, and also because there is a clear urban heat island effect in Toronto [34,35], so stations that acted like the zoo in the 70s and 80s may no longer be representative of the 90s. Finally, instead of averaging the climatic distance ranks across all weather variables considered and selecting one weather station, this study retrieved data from the most representative station for each weather variable considered. Table 1 shows the results of the climatic distance analysis and Figure 1 is a map of the study area, showing the Toronto (Metro) Zoo and the five surrounding weather stations that were evaluated. The daily-scale weather variables that were of interest to this study were the maximum temperature (Tmax), minimum temperature (Tmin), total precipitation (Ptot), and maximum wind speed (Wspd). Based on the results of the climatic distance analysis, Tmax data was retrieved from the Toronto downtown station, while Tmin and Ptot data came from the Oshawa station. Wspd data was taken from Buttonville Airport; seeing that there was no Wspd data recorded at the Metro zoo to evaluate Cdist, data was taken from the closest station by default.

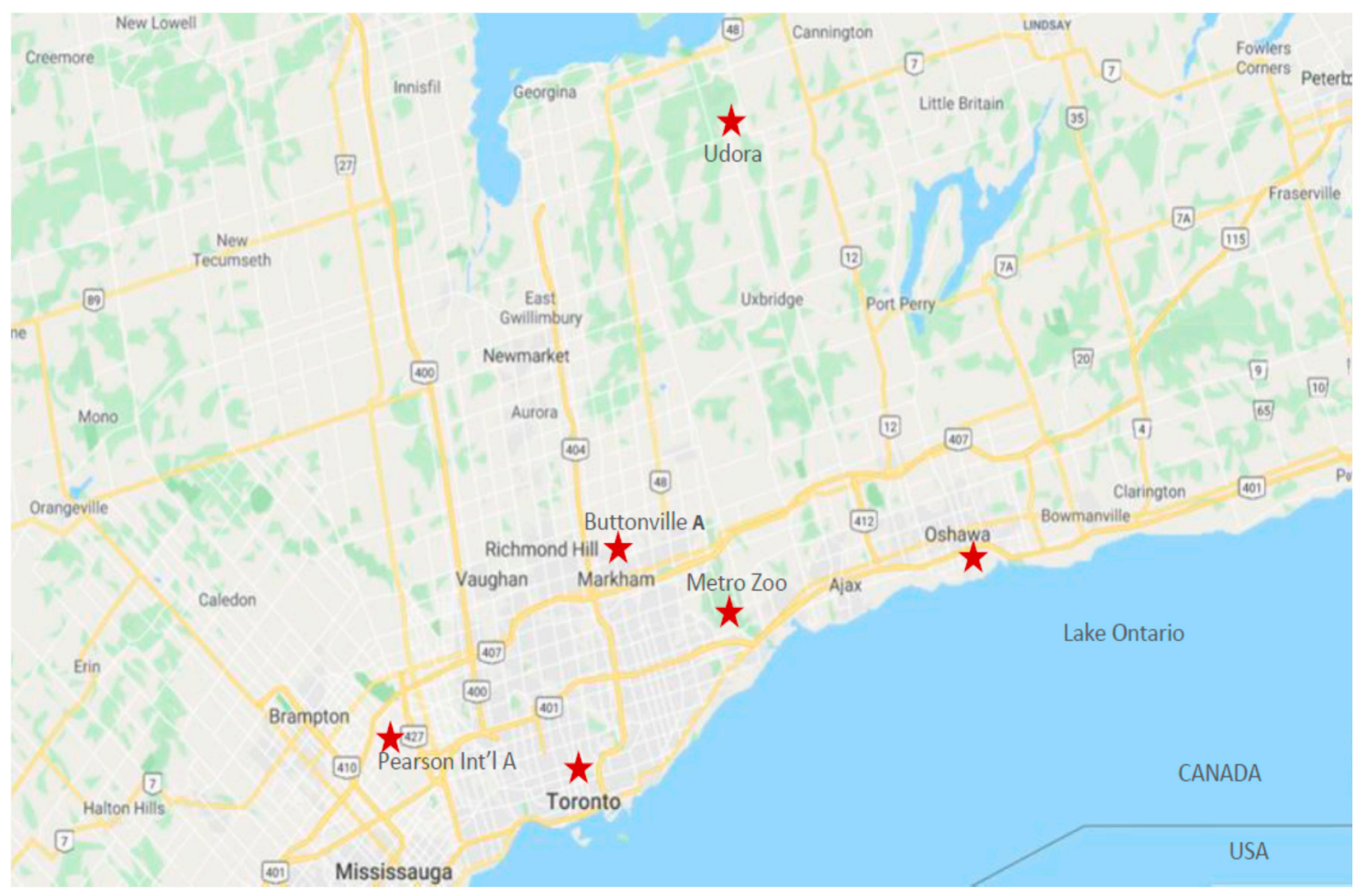

Figure 1. A map of the Greater Toronto Area in southern Ontario (Canada), including the Toronto (Metro) Zoo, as well as five surrounding weather stations. 
Table 1. The proximity (physical distance) of five surrounding weather stations in relation to the Toronto (Metro) Zoo and their climatic distance (Cdist) based on daily weather data from 1990 to 1992.

\begin{tabular}{cccccccc}
\hline Station & $\mathbf{k m}$ & Tmax Cdist & Tmax Rank & Tmin Cdist & Tmin Rank & Ptot Cdist & Ptot Rank \\
\hline Buttonville & 15.3 & 0.157 & 3 & 0.273 & 3 & 0.801 & 3 \\
Toronto & 23.6 & 0.125 & 1 & 0.351 & 5 & 0.644 & 2 \\
Oshawa & 27.6 & 0.185 & 4 & 0.207 & 1 & 0.641 & 1 \\
Pearson & 37.8 & 0.148 & 2 & 0.271 & 2 & 0.845 & 4 \\
Udora & 49.8 & 0.219 & 5 & 0.298 & 4 & 0.919 & 5 \\
\hline
\end{tabular}

Furthermore, the revealed temperature, precipitation, and wind speed thresholds from the work of Hewer and Gough [5] were also tested, in addition to the extreme weather thresholds. Additionally, the theories of Dwyer [36] and Smith [37] were tested, which suggest that above average temperatures in the winter will cause tourism participation to increase, while above average temperatures in the summer will cause tourism participation to decrease. Finally, binary thresholds for precipitation and wind speed were also assessed to determine the effect of any presence of precipitation or measured wind speed on zoo attendance, compared to the effect of extreme precipitation and wind speeds.

This study treats seasons differently than any other tourism climatology paper that focused on zoo attendance [4-10]. The reason for this unique treatment of seasons is due to the methodology designed to determine the effect of extreme weather events. To explain, in order for the methods to be reliable, any months combined into one season for the purpose of analysis must have similar temperatures and attendance levels, otherwise we will be comparing differences in attendance between months rather than differences in zoo attendance between days with extreme and non-extreme weather conditions. Figure 2 illustrates the monthly seasonality of both average monthly temperatures and average monthly attendance at the Toronto Zoo. From this figure, it is apparent that July and August could be combined to make up the summer peak-season while January and February were combined to make up the winter off-season. However, only June could be used to represent the spring shoulder-season and only September was used to represent the autumn shoulder-season. As a result, certain months were not included in the analysis; nonetheless, the effect of extreme weather events on tourism participation is still captured across all four seasons.

Furthermore, efforts were also made to identify and control for the potentially confounding effects of several non-climatic factors. These factors included increases in attendance due to weekends and holidays [4-6]; increasing attendance due to the progression of time within the observational record [4-6,10]; increasing attendance due to animal stars, such as the giant pandas [9,10], as well as special attractions, such as Dinosaurs Alive [9,10]; and finally, decreasing attendance due to external events, such as the terror attacks in the autumn of 2001 and the SARS disease epidemic in the spring of $2003[9,10]$. For each percentile considered, especially for the most extreme two percentiles (99th, 95th, $<5$ th, and $<1$ st), when the sample sizes were considerably low $(n=8$ to $n=87)$, the days making up those groups were individually examined to determine whether the group was being dominated by any of the above characteristics. Apart from the Family Day holiday weekend in the winter season (which was removed to control for its potentially confounding effect), there did not appear to be any dominating factors that were likely to be skewing the results of this study. It seems that the way in which $10 \%$ of the most usual daily weather conditions are distributed across the 20 years of observations in this study, representing large-scale effects which have been shown to influence participation in general $[4-6,9,10]$, did not have a dominating influence on attendance during extreme weather events. However, while looking for the effects of these non-climatic factors, the combined effects of extreme temperature, extreme precipitation, and extreme windspeed were observed, and are discussed while reporting the results for the related extreme daily weather events. Further scrutiny of potentially confounding variables can be conducted by accessing the Supplementary Materials where the weather-attendance datasets for each season have been uploaded. 


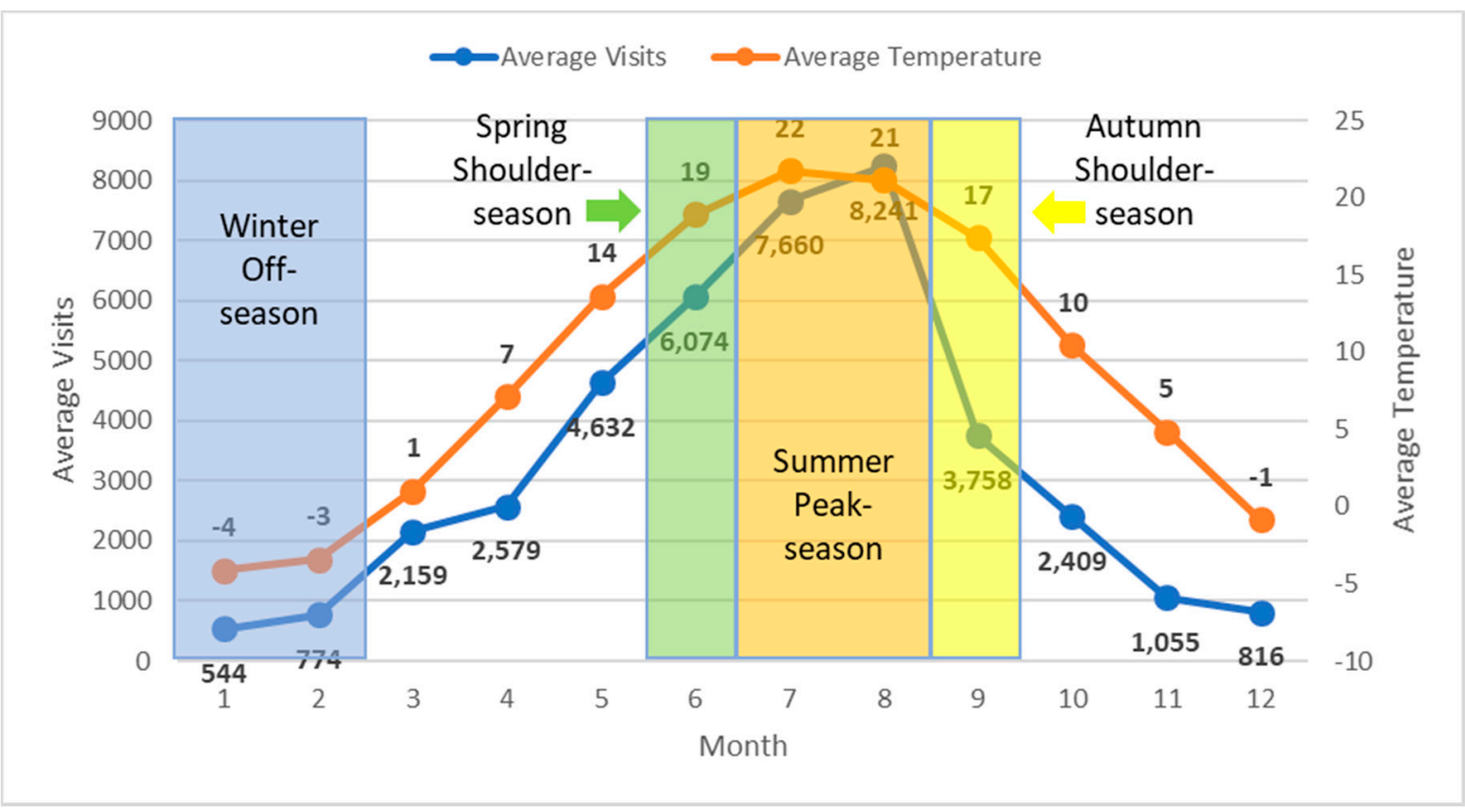

Figure 2. The seasonality of average zoo attendance and average temperature in Toronto (Canada) from 1999 to 2018 (also showing the constitution of the four seasons being analyzed).

\section{Results}

\subsection{Extreme Daytime Temperatures (Daily Maximum Temperature)}

Daily maximum temperatures from 1999 to 2018 at the Toronto Zoo ranged from -16.0 to $19.1{ }^{\circ} \mathrm{C}$, with an average temperature of $0.2^{\circ} \mathrm{C}$, during the winter months of January and February. During the winter off-season, days with usually warm daytime temperatures had a significant effect on zoo attendance (Table 2A). Specifically, days with the warmest $5 \%$ of winter temperatures $\left(>9{ }^{\circ} \mathrm{C}\right)$ had the greatest effect on zoo attendance, resulting in an average of 950 additional visitors and a $187 \%$ increase compared to attendance on winter days when temperatures were not extreme (ranging from -7 to $7{ }^{\circ} \mathrm{C}, n=899$ ). The theoretical threshold represents average winter temperatures, revealing that when temperatures were above average, zoo attendance increased on average by 385 visitors, demonstrating a $114 \%$ increase compared to attendance on days when winter temperatures were below average. Days with extremely cold daytime winter temperatures had a significantly negative effect on average daily zoo attendance, where days with the coldest $1 \%$ of winter temperatures $\left(<13^{\circ} \mathrm{C}\right)$ resulted in an average of 410 fewer visitors, representing an $81 \%$ reduction in zoo attendance compared to days when temperatures were not extreme. It is also worth noting that although the usually warm thresholds resulted in a greater magnitude of change, the extreme cold thresholds recorded a greater statistical significance. This is likely because the average daily attendance in the winter is only 538 people. Therefore, only that many people could decide not to come in response to extreme cold, whereas there is no limit to how many additional people could come in response to usually warm winter temperatures.

Daily maximum temperatures during the spring shoulder-season month of June ranged from 13.3 to $34.2{ }^{\circ} \mathrm{C}$, with an average spring temperature of $24.2{ }^{\circ} \mathrm{C}$. Usually cold temperatures had a greater effect on zoo attendance than extreme heat during the month of June (Table 2B). The greatest effect on zoo attendance was observed during days with the coldest $2 \%$ of June temperatures $\left(<15.4^{\circ} \mathrm{C}\right)$, resulting in an average of 2750 fewer visitors and a $43 \%$ reduction compared to days when temperatures were not extreme in the month of June (ranging from 18.5 to $30.1{ }^{\circ} \mathrm{C}, n=469$ ). The greatest effect that extreme heat had on zoo attendance was observed during the hottest $2 \%$ of days $\left(>33.2{ }^{\circ} \mathrm{C}\right)$, when average daily attendance dropped by 1380 visitors, indicating a $22 \%$ reduction compared to days in June when 
temperatures were not extreme. Hewer and Gough [5] reported a revealed temperature threshold of $>26^{\circ} \mathrm{C}$ during the shoulder seasons (March to June and September to October), for attendance at the Toronto Zoo. This revealed temperature threshold was confirmed within the current study, showing that when temperatures exceeded $26^{\circ} \mathrm{C}$, average zoo attendance decreased by 500 visitors; an $8 \%$ reduction compared to attendance on days when daily maximum temperatures during June were equal to or less than $26^{\circ} \mathrm{C}$. However, the results also demonstrate that warmer temperatures beyond the revealed threshold cause zoo attendance to decline at an even greater rate.

Table 2. The effect of extreme daytime temperatures (daily maximum) on zoo attendance in Toronto, across four different seasons.

\begin{tabular}{|c|c|c|c|c|c|c|}
\hline Threshold & Condition $\left({ }^{\circ} \mathrm{C}\right)$ & $n$ & Mean $\Delta$ & $\% \Delta$ & $\mathbf{t}$ & $p$ \\
\hline \multicolumn{7}{|c|}{ A-Winter Off-Season (January and February) } \\
\hline 99th & $>13.3$ & 12 & 756.7 & $149 \%$ & 1.868 & 0.044 \\
\hline 95th & $>9$ & 57 & 949.9 & $187 \%$ & 4.292 & $<0.001$ \\
\hline 90th & $>7$ & 112 & 621.9 & $122 \%$ & 4.668 & $<0.001$ \\
\hline Theoretical & $>0.2$ & 586 & 384.6 & $114 \%$ & 10.027 & $<0.001$ \\
\hline$<10$ th & $<7$ & 113 & -316.7 & $-62 \%$ & -13.5 & $<0.001$ \\
\hline$<5$ th & $<9$ & 59 & -352.2 & $-69 \%$ & -14.087 & $<0.001$ \\
\hline$<1$ st & $<13$ & 13 & -410.1 & $-81 \%$ & -17.186 & $<0.001$ \\
\hline \multicolumn{7}{|c|}{ B-Spring Shoulder-Season (June) } \\
\hline 98th & $>33.2$ & 11 & -1378.8 & $-22 \%$ & -2.388 & 0.018 \\
\hline 95th & $>31.5$ & 30 & -633.3 & $-10 \%$ & -1.843 & 0.037 \\
\hline 90th & $>30.1$ & 59 & -694.7 & $-11 \%$ & -2.629 & 0.005 \\
\hline Revealed & $>26$ & 213 & -497.1 & $-8 \%$ & -2.380 & 0.009 \\
\hline$<10$ th & $<18.5$ & 57 & -2119.0 & $-33 \%$ & -6.419 & $<0.001$ \\
\hline$<5$ th & $<17.2$ & 30 & -2267.0 & $-35 \%$ & -4.770 & $<0.001$ \\
\hline$<2$ nd & $<15.4$ & 12 & -2750.4 & $-43 \%$ & -4.663 & $<0.001$ \\
\hline \multicolumn{7}{|c|}{ C-Summer Peak-Season (July and August) } \\
\hline 99th & $>34.7$ & 12 & -4352.7 & $-53 \%$ & -7.792 & $<0.001$ \\
\hline 95th & $>32.6$ & 62 & -2969.9 & $-36 \%$ & -10.390 & $<0.001$ \\
\hline 90th & $>31.4$ & 120 & -2477.6 & $-30 \%$ & -11.168 & $<0.001$ \\
\hline Revealed & $>28$ & 417 & -1554.2 & $-18 \%$ & -8.995 & $<0.001$ \\
\hline$<10$ th & $<22.5$ & 127 & -122.8 & $-1 \%$ & -0.420 & 0.338 \\
\hline$<5$ th & $<21.5$ & 64 & -665.1 & $-8 \%$ & -1.650 & 0.052 \\
\hline$<1$ st & $<19.9$ & 15 & -2305.7 & $-28 \%$ & -3.002 & 0.005 \\
\hline \multicolumn{7}{|c|}{ D-Autumn Shoulder-Season (September) } \\
\hline 98th & $>31.2$ & 11 & -770.1 & $-20 \%$ & -0.987 & 0.172 \\
\hline 95th & $>30.4$ & 23 & -422.6 & $-11 \%$ & -0.663 & 0.257 \\
\hline 90th & $>28.1$ & 60 & -298.5 & $-8 \%$ & -0.745 & 0.229 \\
\hline Revealed & $>26$ & 122 & 81.95 & $2 \%$ & 0.252 & 0.401 \\
\hline$<10$ th & $<17.3$ & 59 & -834.6 & $-22 \%$ & -1.984 & 0.025 \\
\hline$<5$ th & $<15.8$ & 30 & -1593.2 & $-41 \%$ & -3.570 & $<0.001$ \\
\hline$<2$ nd & $<14.8$ & 13 & -1239.1 & $-32 \%$ & -1.452 & 0.085 \\
\hline
\end{tabular}

During the summer months of July and August, daily maximum temperatures ranged from 17.2 to $38.2^{\circ} \mathrm{C}$, with an average summer temperature of $26.7^{\circ} \mathrm{C}$. Extreme heat had a greater effect on zoo attendance than usually cold temperatures in the summer months of July and August (Table 2C). The greatest effect was observed when the hottest $1 \%$ of temperatures $\left(>34.7^{\circ} \mathrm{C}\right)$ were recorded, resulting in an average of 4353 fewer visitors and a 53\% reduction compared to summer attendance on days when temperatures were not extreme (ranging from 22.5 to $31.4^{\circ} \mathrm{C}, n=984$ ). The revealed temperature threshold of $>28^{\circ} \mathrm{C}$ for attendance during the peak season at the Toronto Zoo reported by Hewer and Gough [5] was confirmed by the results of this study, but it was also found that as temperatures got warmer, an increasingly greater rate of decline in zoo attendance was observed. The coldest $1 \%$ of days also had a significantly negative effect on zoo attendance in the summer, with average daily 
attendance dropping by 2306 visitors, representing a 28\% decrease, compared to attendance on days when temperatures were not considered extreme.

During the autumn shoulder-season month of September, daily maximum temperatures ranged from 9.5 to $34.1^{\circ} \mathrm{C}$, with an average daytime temperature of $22.5^{\circ} \mathrm{C}$. The autumn shoulder-season was by far the least sensitive to daytime temperature extremes, with only usually cold temperatures having a significant effect on zoo attendance (Table 2D). Although days that recorded extreme heat $\left(>28^{\circ} \mathrm{C}\right)$ did result in fewer visitors than on days with non-extreme temperatures, the differences were not statistically significant. Furthermore, even the revealed shoulder-season temperature threshold of $>26{ }^{\circ} \mathrm{C}[5]$ was not found to be statistically significant during the month of September. The greatest effect on zoo attendance was observed on days when the coldest $5 \%$ of September temperatures were recorded $\left(<15.8^{\circ} \mathrm{C}\right)$, resulting in 1593 fewer visitors and a $41 \%$ reduction compared to attendance on days when temperatures were not considered to be extreme (ranging from 17.3 to $28.1^{\circ} \mathrm{C}, n=473$ ).

Overall, the winter off-season was found to be most sensitive to daytime temperature extremes, exhibiting statistically significant differences between means for all temperature thresholds considered. Furthermore, the winter season also recorded the highest $t$ statistics and resulted in the greatest percent changes. Although the spring shoulder-season was also highly sensitive to extreme daytime temperatures, the greatest magnitude of change occurred during the summer peak-season, mainly because the peak season records the highest number of average daily visitors. Therefore, even when the percent change was smaller, the actual number of visitors that responded to the temperature threshold was considerably greater. For example, the most influential threshold in the winter $\left(>9^{\circ} \mathrm{C}\right)$ resulted in a $187 \%$ increase in average daily visitors, but was only equal to an additional 950 visitors, whereas the most influential threshold in the summer $\left(>34.7^{\circ} \mathrm{C}\right)$ only resulted in a $53 \%$ decrease in average daily attendance, but was equal to 4353 fewer visitors.

\subsection{Extreme Nighttime Temperatures (Daily Minimum Temperature)}

Daily minimum temperatures for the Toronto Zoo from 1999 to 2018 during the winter months of January and February ranged from -26.7 to $7{ }^{\circ} \mathrm{C}$, with an average nighttime temperature of $-7.9^{\circ} \mathrm{C}$. During the winter off-season, usually warm winter temperatures caused average daily attendance to increase and extremely cold winter temperatures caused average daily attendance to decrease (Table 3A). Although the greatest magnitude of change in zoo attendance was observed in response to usually warm winter temperatures, the extreme cold thresholds demonstrated a greater statistical power and significance. The most influential temperature threshold was observed when the warmest $5 \%$ of days occurred $\left(>2{ }^{\circ} \mathrm{C}\right)$, resulting in an average of 595 additional visitors and a $113 \%$ increase compared to zoo attendance on days when nighttime temperatures were not considered to be extreme (ranging from -16.9 to $+0.5^{\circ} \mathrm{C}, n=891$ ). The theoretical threshold associated with average winter temperatures $\left(>7.9^{\circ} \mathrm{C}\right)$ was also highly significant, indicating that when winter temperatures were above average, zoo attendance increased by $81 \%$ (307 additional visitors, on average) when compared to attendance on days when temperatures were below average. Finally, the most influential extreme cold threshold was associated with days when the coldest $1 \%$ of winter temperatures were recorded, resulting in a $75 \%$ reduction in average daily attendance, or 392 fewer visitors, when compared to days when temperatures were not considered extreme.

During the spring shoulder-season month of June, daily minimum temperatures ranged from 3.5 to $22.5^{\circ} \mathrm{C}$, with an average nighttime temperature of $13.58^{\circ} \mathrm{C}$. Interestingly, visitors seemed to have a significant aversion to hot nights during the spring shoulder-season month of June, to such a degree that when nighttime temperatures were warmer than average, zoo attendance decreased by an average of 527 visitors, revealing a $8 \%$ reduction compared to attendance when June temperatures were below average (Table 3B). Looking at the usually cold thresholds, only the less than 10th percentile threshold resulted in significant differences, but suggested that when the coldest $10 \%$ of nighttime temperatures were recorded in the month of June, average daily zoo attendance increased by 907 visitors, representing a $15 \%$ increase compared to days when minimum temperatures were not extreme 
(this threshold demonstrated the greatest magnitude of effect on zoo attendance). Conversely, the most influential extreme heat threshold was associated with the warmest $5 \%$ of nights in June $\left(>19{ }^{\circ} \mathrm{C}\right)$, resulting in an average of 760 fewer visitors and a 13\% reduction compared to zoo attendance on days when minimum temperatures were not considered to be extreme (ranging from 9.4 to $18{ }^{\circ} \mathrm{C}, n=476$ ).

Table 3. The effect of extreme nighttime temperatures on zoo attendance in Toronto, across four different seasons.

\begin{tabular}{|c|c|c|c|c|c|c|}
\hline Threshold & Condition $\left({ }^{\circ} \mathrm{C}\right)$ & $n$ & Mean $\Delta$ & $\% \Delta$ & $\mathbf{t}$ & $p$ \\
\hline \multicolumn{7}{|c|}{ A-Winter Off-Season (January and February) } \\
\hline 99th & $>4$ & 10 & 510.5 & $97 \%$ & 1.678 & 0.064 \\
\hline 95th & $>2$ & 45 & 594.8 & $113 \%$ & 3.211 & 0.001 \\
\hline 90th & $>0.5$ & 103 & 472.6 & $90 \%$ & 4.087 & $<0.001$ \\
\hline Theoretical & $>7.9$ & 579 & 306.9 & $81 \%$ & 7.819 & $<0.001$ \\
\hline$<10$ th & $<16.9$ & 132 & -274.6 & $-52 \%$ & -9.217 & $<0.001$ \\
\hline$<5$ th & $<19.3$ & 60 & -326.0 & $-62 \%$ & -8.972 & $<0.001$ \\
\hline$<1$ st & $<23$ & 12 & -391.7 & $-75 \%$ & -9.511 & $<0.001$ \\
\hline \multicolumn{7}{|c|}{ B-Spring Shoulder-Season (June) } \\
\hline 98th & $>20$ & 8 & -865.3 & $-14 \%$ & -1.149 & 0.144 \\
\hline 95th & $>19$ & 20 & -759.6 & $-13 \%$ & -1.719 & 0.050 \\
\hline 90th & $>18$ & 46 & -754.7 & $-12 \%$ & -2.851 & 0.003 \\
\hline Theoretical & $>13.6$ & 296 & -526.8 & $-8 \%$ & -2.553 & 0.005 \\
\hline$<10$ th & $<9.4$ & 62 & 907.3 & $15 \%$ & 2.248 & 0.014 \\
\hline$<5$ th & $<8$ & 30 & 237.7 & $4 \%$ & 0.437 & 0.333 \\
\hline$<2$ nd & $<7$ & 13 & 443.9 & $7 \%$ & 0.514 & 0.308 \\
\hline \multicolumn{7}{|c|}{ C-Summer Peak-Season (July and August) } \\
\hline 99th & $>23.5$ & 14 & -3018.6 & $-39 \%$ & -8.273 & $<0.001$ \\
\hline 95th & $>21.5$ & 54 & -2422.3 & $-31 \%$ & -8.263 & $<0.001$ \\
\hline 90th & $>20.5$ & 104 & -2036.0 & $-26 \%$ & -8.403 & $<0.001$ \\
\hline Revealed & $>18$ & 315 & -1881.3 & $-23 \%$ & -10.322 & $<0.001$ \\
\hline$<10$ th & $<12.5$ & 164 & 1654.0 & $21 \%$ & 6.929 & $<0.001$ \\
\hline$<5$ th & $<11.5$ & 87 & 1798.2 & $23 \%$ & 5.242 & $<0.001$ \\
\hline$<1$ st & $<9.5$ & 16 & 2938.9 & $37 \%$ & 3.995 & $<0.001$ \\
\hline \multicolumn{7}{|c|}{ D-Autumn Shoulder-Season (September) } \\
\hline 98th & $>20.5$ & 11 & -1068.6 & $-28 \%$ & -1.332 & 0.105 \\
\hline 95th & $>19.5$ & 27 & -395.4 & $-10 \%$ & -0.687 & 0.249 \\
\hline 90th & $>18$ & 50 & -446.8 & $-12 \%$ & -1.036 & 0.152 \\
\hline Theoretical & $>12.3$ & 308 & 13.7 & $0 \%$ & 0.049 & 0.480 \\
\hline$<10$ th & $<7.5$ & 78 & 4.7 & $0 \%$ & 0.012 & 0.495 \\
\hline$<5$ th & $<5.2$ & 31 & -180.5 & $-5 \%$ & -0.333 & 0.371 \\
\hline$<2$ nd & $<4$ & 12 & 108.3 & $3 \%$ & 0.121 & 0.453 \\
\hline
\end{tabular}

Daily minimum temperatures during the summer peak-season months of July and August for the Toronto Zoo ranged from 6.5 to $25^{\circ} \mathrm{C}$, with an average nighttime temperature of $16.2^{\circ} \mathrm{C}$. Summer season zoo attendance was highly sensitive to both extremely hot nighttime temperatures and usually cold nighttime temperatures, where hot nights caused daily zoo attendance to decline and cold night caused daily zoo attendance to increase (Table 3C). The most influential nighttime temperature threshold was observed when the warmest $1 \%$ of summer temperatures were recorded $\left(>23.5^{\circ} \mathrm{C}\right)$, resulting in an average of 3019 fewer daily visitors; a 39\% reduction compared to attendance on days when minimum temperatures were not considered extreme $\left(12.5\right.$ to $\left.20.5^{\circ} \mathrm{C}, n=926\right)$. Interestingly, the next most influential nighttime temperature threshold was observed when the coldest $1 \%$ of summer temperatures were recorded $\left(<9.5^{\circ} \mathrm{C}\right)$, resulting in the inverse effect, and causing average daily zoo attendance to decline by 2939 visitors, representing a $37 \%$ reduction compared to days when minimum temperatures were not considered to be extreme. Finally, the revealed nighttime temperature threshold of $>18{ }^{\circ} \mathrm{C}$ [5] was confirmed and was even associated with the greatest statistical power among 
thresholds $(\mathrm{t}=-10.322, p<0.001)$, resulting in 1881 fewer visitors on average and a $23 \%$ reduction compared to days when minimum summer temperatures were less than or equal to $18^{\circ} \mathrm{C}$.

During the autumn shoulder-season month of September, daily minimum temperatures ranged from 1.5 to $23^{\circ} \mathrm{C}$, with an average nighttime temperature of $12.3^{\circ} \mathrm{C}$. The autumn season was by far the least sensitive to extreme nighttime temperatures, seeing that none of the tested thresholds resulted in statistically significant differences between means (Table 3D). In the month of September, zoo visitors were no longer as sensitive to extremely warm nights as they were in the spring shoulder-season month of June, despite the same temperature extremes being observed and tested. Zoo visitors in the month of September were also not positively impacted by usually cool nights, like they were in the summer months, probably because usually cool nights in September are much colder than they are in the summer. Finally, zoo visitors in the month of September were generally not sensitive to temperature variability, in that even the theoretical threshold which compared attendance on days with above average minimum temperatures to attendance on days with below average minimum temperatures did not return any statistically significant results (resulting in an average of only five additional visitors, representing a $0 \%$ difference between means for these two groups).

Overall, zoo attendance during the summer peak-season months of July and August was most sensitive to extreme nighttime temperatures, exhibiting both the greatest magnitude of effect on average daily visitors and the greatest statistical power among tests. However, the winter off-season months of January and February were also highly sensitive to extreme nighttime temperatures, displaying the greatest percent change associated with attendance on days with extreme minimum temperatures compared to days with normal minimum temperatures. Interestingly, the shoulder-season months of June and September were the least sensitive to extreme nighttime temperatures, which is contrary to the findings related to the sensitivity of zoo attendance to weather variability in general $[5,6]$.

\subsection{Extreme Precipitation (Daily Total Precipitation)}

Total daily precipitation during the winter off-season months of January and February in Toronto from 1999 to 2018 ranged from 0 to $35 \mathrm{~mm}$, exhibiting a seasonal average of $2.0 \mathrm{~mm}$, making the winter season the driest season of the year. The winter season was the least sensitive to daily precipitation extremes, but was still sensitive to precipitation in general (Table 4A). For example, neither the 99th percentile of daily precipitation $(>21 \mathrm{~mm}$ ) nor the 95th percentile of daily precipitation $(>10.6 \mathrm{~mm})$ resulted in statistically significant differences between means for zoo attendance, when compared to days when total precipitation was not considered to be extreme (ranging from 0 to $6.2 \mathrm{~mm}, n=1013$ ). Looking closer at this finding, it was determined that above average temperatures on a weekend in the winter had an overriding effect over the influence of extreme precipitation, thereby confounding the results on the 99th and 95th percentile thresholds. The overriding effect of warm weekends against extreme precipitation for zoo attendance is contrary to the contentions of de Freitas $(1990,2003,2016)$ for beach tourism, which state that precipitation and wind have an overriding effect on ideal temperatures. Although the wettest $10 \%$ of days during the winter season did result in a statistically significant decline in daily zoo attendance, the magnitude of the effect and significance of the results were not as pronounced as they were for the revealed $(>2 \mathrm{~mm}$ ) and binary thresholds $(>0 \mathrm{~mm}$ ) thresholds, to such a degree that the greatest influence on daily zoo attendance was observed when comparing days with precipitation to days without precipitation. In this case, days with precipitation recorded an average of 152 fewer visitors, representing a $26 \%$ reduction compared to days with no precipitation.

During the spring shoulder-season month of June, total daily precipitation ranged from 0 to $67.4 \mathrm{~mm}$, with a seasonal average of $3.16 \mathrm{~mm}$, making the spring season the wettest season in the year. Daily zoo attendance was highly sensitive to precipitation extremes and precipitation in general during the month of September (Table 4B). The most influential effect on zoo attendance was observed during the wettest $2 \%$ of days in the spring $(>26.7 \mathrm{~mm}$ ), resulting in an average of 2253 fewer visitors, which is a $36 \%$ reduction compared to attendance on days when precipitation was not extreme (ranging from 0 to $10.2 \mathrm{~mm}, n=525$ ). The revealed threshold ( $>2 \mathrm{~mm}$ ) reported by Hewer and Gough [5] 
was found to be highly significant, but it is worth noting that as precipitation increased, the effect on attendance became more pronounced, and the binary threshold ( $>0 \mathrm{~mm}$ ) was more influential than the revealed threshold.

Table 4. The effect of extreme precipitation on zoo attendance in Toronto, across four different seasons.

\begin{tabular}{|c|c|c|c|c|c|c|}
\hline Threshold & Condition (mm/d) & $n$ & Mean $\Delta$ & $\% \Delta$ & $\mathbf{t}$ & $p$ \\
\hline \multicolumn{7}{|c|}{ A-Winter Off-Season (January \& February) } \\
\hline 99th & $>21$ & 12 & 205.7 & $38 \%$ & 0.427 & 0.339 \\
\hline 95th & $>10.6$ & 57 & -126.0 & $-23 \%$ & -1.141 & 0.129 \\
\hline 90th & $>6.2$ & 113 & -118.5 & $-22 \%$ & -1.644 & 0.051 \\
\hline Revealed & $>2$ & 261 & -144.1 & $-25 \%$ & -3.322 & 0.000 \\
\hline Wet/Dry & $>0$ & 446 & -152.4 & $-26 \%$ & -3.928 & 0.000 \\
\hline \multicolumn{7}{|c|}{ B-Spring Shoulder-Season (June) } \\
\hline 98th & $>26.7$ & 12 & -2253.0 & $-36 \%$ & -5.503 & $<0.001$ \\
\hline 95th & $>17.6$ & 29 & -2037.9 & $-32 \%$ & -5.729 & $<0.001$ \\
\hline 90th & $>10.2$ & 59 & -1918.2 & $-31 \%$ & -6.543 & $<0.001$ \\
\hline Revealed & $>2$ & 152 & -1733.5 & $-27 \%$ & -7.926 & $<0.001$ \\
\hline Wet/Dry & $>0$ & 234 & -1780.5 & $-26 \%$ & -9.063 & $<0.001$ \\
\hline \multicolumn{7}{|c|}{ C-Summer Peak-Season (July \& August) } \\
\hline 99th & $>35$ & 12 & -995.1 & $-12 \%$ & -1.014 & 0.166 \\
\hline 95th & $>15.4$ & 59 & -1712.9 & $-21 \%$ & -4.234 & $<0.001$ \\
\hline 90th & $>8$ & 120 & -1889.5 & $-23 \%$ & -6.773 & $<0.001$ \\
\hline Revealed & $>2$ & 238 & -1995.3 & $-24 \%$ & -9.486 & $<0.001$ \\
\hline Wet/Dry & $>0$ & 397 & -1834.1 & $-22 \%$ & -10.178 & $<0.001$ \\
\hline \multicolumn{7}{|c|}{ D-Autumn Shoulder-Season (September) } \\
\hline 98th & $>25.4$ & 11 & -2128.0 & $-54 \%$ & -3.784 & 0.001 \\
\hline 95th & $>18$ & 30 & -1626.7 & $-41 \%$ & -3.499 & 0.001 \\
\hline 90th & $>9.4$ & 60 & -1685.0 & $-43 \%$ & -4.960 & $<0.001$ \\
\hline Revealed & $>2$ & 131 & -1298.8 & $-32 \%$ & -4.483 & $<0.001$ \\
\hline Wet/Dry & $>0$ & 194 & -1202.9 & $-29 \%$ & -4.472 & $<0.001$ \\
\hline
\end{tabular}

Total daily precipitation during the summer peak-season months of July and August ranged from 0 to $73.5 \mathrm{~mm}$ (which is the greatest daily precipitation extreme observed across all four seasons), recording a seasonal average of $2.55 \mathrm{~mm}$. Both daily precipitation extremes and the occurrence of daily precipitation in general had significantly negative effects on zoo attendance during the summer season (Table 4C). Although the summer season did not record the greatest magnitude of effect on attendance, or the greatest percentage of change, it was associated with the greatest statistical power across tests, likely due to the greater sample size associated with combining two months compared to only one month in the spring and autumn. Nonetheless, the greatest magnitude of effect and percent change associated with precipitation during the summer season was observed when testing the revealed threshold ( $>2 \mathrm{~mm}$ ) reported by Hewer and Gough [5]; where days with more than $2 \mathrm{~mm}$ of rain resulted in 1995 fewer visitors on average, representing a 24\% reduction in attendance compared to days with less than or equal to $2 \mathrm{~mm}$ of rain. One additional aspect to note relates to the finding that the 99th percentile of daily precipitation did not have a statistically significant effect on zoo attendance. When looking closer at this finding, it was determined that mild weekends during the summer were often associated with above average attendance, even with the occurrence of extreme precipitation, thereby confounding the results of the analysis for the 99th percentile of summer precipitation.

During the autumn shoulder-season month of September, total daily precipitation ranged from 0 to $50 \mathrm{~mm}$, with a seasonal average of $2.88 \mathrm{~mm}$. September zoo attendance was highly sensitive to both extreme precipitation and the occurrence of precipitation in general (Table 4D). Although the spring season recorded a greater magnitude of effect on zoo attendance for extreme precipitation, the autumn season recorded a higher percentage change, when comparing attendance on days with extreme precipitation to days with normal precipitation (ranging from 0 to $9.4 \mathrm{~mm}, n=533$ ). The 
most influential precipitation threshold was associated with the wettest $2 \%$ of days, which caused zoo attendance to decline by an average of 2128 visitors, indicating a $54 \%$ reduction compared to days when daily precipitation was not considered to be extreme. Finally, both the binary $(>0 \mathrm{~mm})$ and revealed $(>2 \mathrm{~mm}$ ) thresholds had highly significant negative effects of daily zoo attendance, but the magnitude of influence did not plateau there, as suggested by Hewer and Gough [5]; rather, it continued to increase in magnitude as the amount of precipitation increased.

\subsection{Extreme Wind Speed (Daily Maximum Wind Speed)}

The daily maximum wind speed in Toronto from 1999 to 2018 during the winter season months of January and February ranged from $<31$ to $93 \mathrm{~km} / \mathrm{h}$, and when counting $<31$ as zero, the average daily wind speed was $26.3 \mathrm{~km} / \mathrm{h}$ during the winter season, making winter the windiest season. Compared to the other three seasons, the winter season was the least sensitive to extreme wind speeds (Table 5A). Looking at both the revealed threshold $(>40 \mathrm{~km} / \mathrm{h})$ and the binary threshold $(>30 \mathrm{~km} / \mathrm{h})$, increasing wind speeds had a significantly negative effect on average daily zoo attendance during the winter season. The greatest effect was observed in relation to the revealed threshold of Hewer and Gough [5], resulting in 70 fewer visitors on average and a 12\% reduction when compared to attendance on days with wind speeds less than or equal to $40 \mathrm{~km} / \mathrm{h}$. It is important to note, however, that it is very likely that the insignificant results from the percentile thresholds associated with extreme wind speeds may have been confounded by the coincidence of warm weekends; where, once again, warm weekends displayed a higher than average attendance, despite the coinciding presence of high winds.

During the spring shoulder-season month of June, the maximum daily wind speed ranged from $<31$ to $87 \mathrm{~km} / \mathrm{h}$, with an average daily wind speed on $20.6 \mathrm{~km} / \mathrm{h}$ (when counting the $<31 \mathrm{~km} / \mathrm{h}$ text entry as “ 0 "). June was more sensitive to extreme wind speeds than the winter, but less sensitive than both the summer and September (Table 5B). The 98th percentile of extreme wind speeds was not statistically significant, potentially due to confounding variables like ideal temperatures on weekends, but also possibly because of the small sample size $(n=11)$. However, the top $5 \%$ of windiest days $(>56 \mathrm{~km} / \mathrm{h})$ had the greatest effect on average daily zoo attendance in the spring, causing attendance to decline by 1231 visitors, representing a $20 \%$ reduction when compared to attendance on days when wind speeds were not considered extreme (ranging from $<31$ to $50 \mathrm{~km} / \mathrm{h}, n=534$ ). Once again, the revealed threshold of Hewer and Gough [5] was confirmed by this study, being both highly significant and having the third greatest effect on average daily zoo attendance. Conversely, the binary threshold $(>30$ $\mathrm{km} / \mathrm{h})$ resulted in the greatest statistical power $(\mathrm{t}=-3.821, p<0.001)$, likely because it had the highest sample size $(n=282)$ among thresholds considered. Finally, there may be a correlation between high winds and warm temperatures during the spring season for this study region, where wind brings in warm fronts, displacing the lingering winter cold and showing signs of the approaching summer, thereby potentially confounding the results of the windspeed percentile thresholds.

The daily maximum wind speed during the summer peak season months of July and August ranged from $<31 \mathrm{~km} / \mathrm{h}$ to $109 \mathrm{~km} / \mathrm{h}$, with an average summer wind speed of $18.3 \mathrm{~km} / \mathrm{h}$. The summer season recorded the highest wind speed observed across all seasons $(109 \mathrm{~km} / \mathrm{h})$, and also recorded the most influential wind threshold (Table 5C), with the windiest $1 \%$ of days being associated with 2855 fewer visitors, representing a 35\% reduction when compared to attendance on days when wind conditions were not considered extreme (ranging from $<31$ to $44 \mathrm{~km} / \mathrm{h}, n=1115$ ). Furthermore, both the revealed and binary thresholds were found to have statistically significant negative effects on zoo attendance, with the binary threshold resulting in the strongest statistically power, most likely because it also had the largest sample size $(n=563)$. Finally, it was also apparent that as the wind speed increased across the thresholds considered, so did the negative effect on zoo attendance during the summer season. However, it was found that high winds in the summer are strongly correlated with precipitation events, as strong winds often bring in conflicting fronts that clash with each other and create rain events. Therefore, it is not possible to attribute all the observed effects to extreme wind speeds alone, as daily precipitation likely confounded the results, especially for the 99 th (8 out of 
11 days had rain, $73 \%$ ) and 95th (36 out of 50 days had rain, $72 \%$ ) percentiles. Nonetheless, the negative effect of extreme wind on zoo attendance during the summer months was found to be greater than the negative effect of extreme precipitation, thereby illustrating a combined effect.

Table 5. The effect of an extreme wind speed on zoo attendance in Toronto, across four different seasons.

\begin{tabular}{|c|c|c|c|c|c|c|}
\hline Threshold & Condition $(\mathrm{km} / \mathrm{h})$ & $n$ & Mean $\Delta$ & $\% \Delta$ & $\mathbf{t}$ & $p$ \\
\hline \multicolumn{7}{|c|}{ A-Winter Off-Season (January and February) } \\
\hline 99th & $>70$ & 12 & -96.6 & $-18 \%$ & -0.643 & 0.267 \\
\hline 95th & $>59$ & 57 & 15.0 & $3 \%$ & 0.131 & 0.448 \\
\hline 90th & $>54$ & 112 & 28.6 & $5 \%$ & 0.364 & 0.358 \\
\hline Revealed & $>40$ & 397 & -69.6 & $-12 \%$ & -1.662 & 0.048 \\
\hline Windy/Calm & $>30$ & 662 & -59.0 & $-10 \%$ & -1.393 & 0.082 \\
\hline \multicolumn{7}{|c|}{ B-Spring Shoulder-Season (June) } \\
\hline 98th & $>61$ & 11 & -264.2 & $-4 \%$ & -0.452 & 0.330 \\
\hline 95th & $>56$ & 29 & -1230.9 & $-20 \%$ & -3.120 & 0.002 \\
\hline 90th & $>50$ & 51 & -670.2 & $-11 \%$ & -2.177 & 0.017 \\
\hline Revealed & $>40$ & 131 & -715.6 & $-11 \%$ & -3.134 & 0.001 \\
\hline Windy/Calm & $>30$ & 282 & -778.9 & $-12 \%$ & -3.821 & $<0.001$ \\
\hline \multicolumn{7}{|c|}{ C-Summer Peak-Season (July and August) } \\
\hline 99th & $>65$ & 11 & -2855.3 & $-35 \%$ & -3.672 & 0.002 \\
\hline 95th & $>50$ & 50 & -2008.2 & $-25 \%$ & -4.520 & $<0.001$ \\
\hline 90th & $>44$ & 116 & -1061.8 & $-13 \%$ & -3.138 & 0.001 \\
\hline Revealed & $>40$ & 220 & -980.7 & $-12 \%$ & -4.083 & $<0.001$ \\
\hline Windy/Calm & $>30$ & 563 & -859.3 & $-10 \%$ & -4.976 & $<0.001$ \\
\hline \multicolumn{7}{|c|}{ D-Autumn Shoulder-Season (September) } \\
\hline 98th & $>61$ & 10 & -2726.1 & $-70 \%$ & -8.374 & $<0.001$ \\
\hline 95th & $>50$ & 24 & -1878.3 & $-49 \%$ & -3.748 & $<0.001$ \\
\hline 90th & $>46$ & 53 & -1342.1 & $-35 \%$ & -3.258 & $<0.001$ \\
\hline Revealed & $>40$ & 110 & -1082.5 & $-27 \%$ & -3.329 & $<0.001$ \\
\hline Windy/Calm & $>0$ & 250 & -727.1 & $-18 \%$ & -2.608 & $<0.001$ \\
\hline
\end{tabular}

During the autumn shoulder-season month of September, the maximum daily wind speeds ranged from $<31$ to $83 \mathrm{~km} / \mathrm{h}$, with an average autumn wind speed of 17.07, making the autumn the least windy season. Daily zoo attendance in September was highly sensitive to the maximum wind speed, showing a negative linear relationship where, as the wind speed increased, zoo attendance decreased (Table 5D). The windiest $2 \%$ of days in the month of September $(>61 \mathrm{~km} / \mathrm{h})$ represented the wind threshold with the second greatest magnitude of effect on average daily zoo attendance, resulting in 2726 fewer visitors, being associated with the greatest percent change across wind thresholds; it was equal to $-70 \%$ when compared to attendance on days when wind speeds were not considered extreme (ranging from $<31$ to $46 \mathrm{~km} / \mathrm{h}, n=541$ ). The 98 th percentile threshold for extreme wind speed was also associated with the greatest statistical power among all wind thresholds $(\mathrm{t}=-8.374, p<0.001)$, despite the very small sample size $(n=10)$. However, once again, the windiest days in September were also often associated with rain events, especially the 98 th (7 out of 10 days has rain, 70\%) and 95th (18 out of 24 days had rain, 75\%) percentiles. Furthermore, the effect of extreme rain events on September zoo attendance is very similar to the effect of extreme wind speed. Therefore, precipitation has very likely confounded the results from the windiest $2 \%$ and $5 \%$ of days. Nonetheless, increasing wind speeds were still found to have a statistically significant negative effect on September zoo attendance, as evidenced by the revealed $(>40 \mathrm{~km} / \mathrm{h})$ and binary $(>30 \mathrm{~km} / \mathrm{h})$ wind thresholds.

\section{Discussion}

Looking at the considerable differences in the way tourism participation responded to extreme daily weather events across the seasons, this study emphasizes the importance of defining different seasons 
related to tourism participation for a given activity and analyzing the effect of weather and climate variability, as well as extreme weather events, on those seasons separately. For example, the results of this study indicate that the winter off-season was most sensitive to daytime temperature extremes (maximum temperatures), while the spring shoulder-season was most sensitive to precipitation extremes. Moreover, the summer season was most sensitive to nighttime temperature extremes (minimum temperatures) and the autumn shoulder-season was most sensitive to wind speed extremes. It became clear that each season was associated with its own degree of weather sensitivity to the various weather variables and weather extremes that were explored. This finding has important implications for previous studies that combined many months or even multiple seasons into one season for analysis, especially modeling-based studies that defined weather sensitivity and held that statistical relationship constant within their predictive models. For example, Jones and Scott [14,15] modeled the peak and shoulder seasons for park visitation separately, which was good, but the shoulder season was likely too large and needed to be separated to include an off season, as tourism participation does not respond in the same way to weather and climate variability in the spring as it does in the winter $[23,33]$. Furthermore, Hewer and Gough [5,6] modeled zoo attendance using an off-season and shoulder-season and peak-season model, which was an improvement, but both this study and the analogue study of Hewer and Gough [9] demonstrate that tourism participation does not respond in the same way to weather and climate variability in the spring as it does in the autumn, thus requiring the shoulder seasons to be modeled/analyzed separately. To further support this contention, the modeling studies of Hewer and Gough [5,6] suggested that the shoulder seasons were most weather-sensitive and that tourism participation in both the spring and autumn responded in the same way. However, the analogue study of Hewer and Gough [9] found that the autumn season was the only season not to be affected by seasonal climatic anomalies. Conversely, the current study has found the spring season to have a greater sensitivity to temperature and precipitation extremes, while the autumn was more sensitive to maximum windspeeds.

Considering the revealed weather thresholds reported by Hewer and Gough [5] for zoo attendance in Toronto, the current study validated each of these thresholds across the various seasons for which they applied, apart from maximum temperatures $\left(>26^{\circ} \mathrm{C}\right)$ in the autumn season, which again relates back to the fact that Hewer and Gough [5] combined the spring and autumn into one shoulder season. Furthermore, there were even a few cases where the revealed threshold of Hewer and Gough [5] proved to be the most influential threshold when compared to the thresholds set by the percentiles, as well as the binary thresholds of wet versus dry or windy versus calm. For example, the revealed precipitation threshold of $>2 \mathrm{~mm}$ was found to have the greatest magnitude of effect on zoo attendance during the summer peak-season. Additionally, the revealed windspeed threshold of $>40 \mathrm{~km} / \mathrm{h}$ had the greatest magnitude of effect on zoo attendance during the winter off-season. In the absence of revealed thresholds, we also tested theoretical thresholds defined by the seasonal average, based on the assumptions of Dwyer [36] and Smith [37], who stated that above average temperatures in the winter would increase tourism participation, while above average temperatures in the summer would decrease attendance. This assumption proved true for both maximum and minimum temperatures during the winter. Furthermore, above average temperatures in June caused attendance to decline, but there was no significant effect of above average temperatures in September. Additionally, the binary thresholds of wet versus dry and windy versus calm resulted in statistically significant effects on zoo attendance across all four seasons apart from windspeed in the winter, and in one case, was even the most influential threshold tested (for total precipitation in the winter). The binary thresholds typically indicated the direction of the effect that would be seen among the extreme percentile thresholds, but the binary thresholds often resulted in lesser magnitudes of effect, yet had a stronger statistical power.

Although it was not the focus of the current study, heat waves are an important aspect of extreme weather events, with major implications due to observed and projected warming under global climate change. NOAA [38] defines heat waves as "a period of unusually hot weather that typically lasts two or more days". Conversely, this study only considered the effect of single-day heat extremes. 
Therefore, future research in the field of tourism climatology that develops a novel methodology (due to the absence of any previous studies) that assesses the effect of heat waves (periods with multiple and consecutive days of extreme heat) on human participation in recreation and tourism, remains an important area of future research. Just as the methodology in this current study would be appropriate for application in future research examining other tourism activities beyond zoo attendance, a research methodology designed to assess the impacts of heatwaves on tourism participation would be useful for application with zoo attendance along with other tourism contexts, such as park visitation, beach use, or general sight-seeing.

Finally, this novel method for identifying extreme weather events and determining their effect on human participation in recreation and tourism has important implications for future impacts under projected climate change. Firstly, climate science suggests that extreme weather events are already increasing and will continue to increase, both in frequency and intensity, as the weather and climate become less stable and more variable under future climate change [39]. Therefore, the effects reported in this study are likely to become more frequent and more intense. However, it was found that the effect of extreme daily weather events had both negative and positive implications for zoo attendance in Toronto, depending on the weather variable and operating season. For example, usually warm daytime temperatures had a significantly positive effect on zoo attendance in the winter off-season, but both extreme heat and usually cold temperatures had significantly negative effects on zoo attendance in the spring and summer seasons. Similarly, usually warm nighttime temperatures had a positive effect on participation in the winter, but extremely warm nighttime temperatures had a negative effect in the spring and summer. In comparison, extremely cool nighttime temperatures had a negative effect in the winter, but usually cool nighttime temperatures had a positive effect in the spring and summer. However, when extreme precipitation and wind speeds were found to affect zoo attendance across the seasons, the effects were always negative. The most important finding in relation to climate change impacts and specifically a warmer climate is that extremely warm seasonal temperatures had the greatest influence on zoo attendance, compared to extreme cold, extreme precipitation, and extreme wind speed. In general, therefore, the results of this study suggest that an increasing intensity and frequency of extreme weather events under projected climate change will have negative effects on zoo attendance, especially during the spring shoulder and summer peak seasons, with a slight off-setting effect increasing zoo attendance in the winter season, yet to a much lesser degree. Therefore, future studies attempting to assess the impacts of projected climate change on human participation in recreation and tourism, should endeavor to quantify and include the effects of extreme weather events.

\section{Conclusions}

We will draw some conclusions from the results by identifying which weather variable had the greatest effect on zoo attendance within each season. During the winter off-season months of January and February, the most influential weather variable was the daily maximum temperatures (Tmax), being best represented by the 95th percentile threshold $\left(>9^{\circ} \mathrm{C}\right)$, where average daily attendance increased by 950 visitors $(+187 \%)$, and was found to be statistically significant $(t=4.292, p<0.001)$. For the spring shoulder-season month of June, Tmax was once again the most influential weather variable for zoo attendance, but this time, it was the coolest $2 \%$ of days $\left(<15.4{ }^{\circ} \mathrm{C}\right)$ that had the greatest effect on attendance, causing attendance to decline by an average of 2750 visitors $(-43 \%)$, which was found to be statistically significant $(\mathrm{t}=-4.663, p<0.001)$. During the summer peak-season months of July and August, once again, Tmax was the most influential weather variable, being best represented by the 99th percentile $\left(>34.7^{\circ} \mathrm{C}\right)$, resulting in an average of 4353 fewer visitors $(-53 \%)$; a difference that was statistically significant $(t=-7.792, p<0.001)$. Interestingly, during the autumn shoulder-season month of September, Tmax was not the most influential weather variable. Instead, zoo attendance was more influenced by a combination of total precipitation and maximum wind speed. The most influential weather variable in the month of September was the maximum wind speed, being best represented by the windiest $2 \%$ of days $(>61 \mathrm{~km} / \mathrm{h}$ ), resulting in an average of 2726 fewer visitors $(-70 \%)$, which 
was statistically significant $(t=-8.374, p<0.001)$. However, extreme wind speeds were found to be highly correlated with rain events during the month of September. Therefore, we cannot attribute all of this effect to wind speed alone, since total precipitation likely confounded the results and created a combined effect. Extreme precipitation was also very influential in terms of September zoo attendance, where the wettest $2 \%$ of days $(>25.4 \mathrm{~mm})$ resulted in an average of 2128 fewer visitors each day $(-54 \%)$, which was found to be statistically significant $(t=-3.784, p=0.001)$.

Returning to the NCEI definition of extreme weather events "as lying in the outermost (most unusual) 10 percent of a place's history" [32], this concept was represented by the 90th and the $<10$ th percentiles. This approach for defining extreme weather events and determining their effect on tourism participation was successful, resulting in statistically significant results across all seasons for all weather variables considered, apart from maximum temperatures in the summer, minimum temperatures in the autumn, and wind speed in the winter. However, it was found that testing even more unusual extremes by using the 99th and 95th of the $<1$ st and $<5$ th percentiles also yielded meaningful results, often generating a greater magnitude of effect on tourism participation. For example, these percentiles representing more usual cases of extreme weather events captured the greatest magnitude of effect on tourism participation in all seasons, across all weather variables, except for minimum temperatures in the spring, total precipitation during the winter and summer and the maximum windspeed in the winter. In conclusion, although the 99 th and $<1$ st percentiles often resulted in a greater magnitude of effect on participation compared to the 95th and $<5$ th percentiles, the sample size of these most usual extreme events was very small $(n=10$ to 16$)$ and as a result, sometimes failed to capture the effect that was presented when the sample size increased for the 95 th and $<5$ th percentiles $(n=20$ to 87). Nonetheless, for future research looking to utilize this method for determining the effect of extreme weather events on tourism participation, it is recommended that all three categories of extreme weather events be defined and tested to capture the full picture concerning how human participation in recreation and tourism is affected by the varying intensity of extreme weather events.

Supplementary Materials: The weather-attendance data sets from each season (winter off-season, spring shoulder-season, summer peak-season and autumn shoulder-season) are available as supplementary materials online at http://www.mdpi.com/2073-4433/11/1/99/s1.

Funding: This research received no external funding.

Acknowledgments: The author would like to thank William Gough, Vice-Principal (Academic) and Dean at the University of Toronto in Scarborough, for the funding that made this research possible, employing the author as a Research Associate in the Department of Physical and Environmental Sciences.

Conflicts of Interest: The authors declare no conflicts of interest.

\section{References}

1. De Freitas, C. Recreation climate assessment. Int. J. Climatol. 1990, 10, 89-103. [CrossRef]

2. De Freitas, C. Tourism climatology: Evaluating environmental information for decision making and business planning in the recreation and tourism sector. Int. J. Biometeorol. 2003, 4, 45-54. [CrossRef] [PubMed]

3. De Freitas, C. Weather and place-based human behaviour: Recreational preferences and sensitivity. Int. J. Biometeorol. 2014, 59, 55-63. [CrossRef] [PubMed]

4. Aylen, J.; Albertson, K.; Cavan, G. The impact of weather and climate on tourism demand: The case of Chester Zoo. Clim. Chang. 2014, 127, 183-197. [CrossRef]

5. Hewer, M.; Gough, W. Weather sensitivity for zoo visitation in Toronto, Canada: A quantitative analysis of historical data. Int. J. Biometeorol. 2016, 60, 1645-1660. [CrossRef]

6. Hewer, M.; Gough, W. Assessing the impact of projected climate change on zoo visitation in Toronto (Canada). J. Geogr. Geol. 2016, 8, 30-48. [CrossRef]

7. Perkins, D.; Debbage, K. Weather and tourism: Thermal comfort and zoological park visitor attendance. Atmosphere 2016, 7, 44. [CrossRef]

8. Perkins, D. Using synoptic weather types to predict visitor attendance at Atlanta and Indianapolis zoological parks. Int. J. Biometeorol. 2016, 62, 127-137. [CrossRef] 
9. Hewer, M.; Gough, W. The effect of seasonal climatic anomalies on zoo visitation in Toronto (Canada) and the implications for projected climate change. Atmosphere 2016, 7, 71. [CrossRef]

10. Su, A.; Lin, Y. Factors affecting yearly and monthly visits to Taipei Zoo. Theor. Appl. Climatol. 2019, 135, 463-472. [CrossRef]

11. Wall, G.; Harrison, R.; Kinnaird, V.; McBoyle, G.; Quinlan, C. The implications of climate change for camping in Ontario. J. Recreat. Res. Rev. 1986, 13, 50-60.

12. Richardson, R.; Loomis, J. Adaptive recreation planning and climate change: A contingent visitation approach. Ecol. Econ. 2004, 50, 83-99. [CrossRef]

13. Loomis, J.; Richardson, R. An external validity test of intended behaviour: Comparing revealed preference and intended visitation in response to climate change. J. Environ. Plan. Manag. 2006, 49, 621-630. [CrossRef]

14. Jones, B.; Scott, D. Implications of climate change for visitation to Ontario's provincial parks. Leisure 2006, 30 , 233-261. [CrossRef]

15. Jones, B.; Scott, D. Climate change, seasonality and visitation to Canada's national parks. J. Parks Recreat. Adm. 2006, 24, 42-62.

16. Scott, D.; Jones, B.; Konopek, J. Implications of climate and environmental change for nature-based tourism in the Canadian Rocky Mountains: A case study of Waterton Lakes national park. Tour. Manag. 2007, 28, 570-579. [CrossRef]

17. Scott, D.; Jones, B.; Konopek, J. Exploring the impact of climate-induced environmental changes on future visitation to Canada's Rocky Mountain national parks. Tour. Rev. Int. 2008, 12, 43-56. [CrossRef]

18. Hadwen, W.; Arthington, A.; Boon, P.; Taylor, B.; Fellows, C. Do climatic or institutional factors drive seasonal patterns of tourism visitation to protected areas across diverse climate zones in eastern Australia? Tour. Geogr. 2011, 13, 187-208. [CrossRef]

19. Buckley, L.; Foushee, M. Footprints of climate change in US national park visitation. Int. J. Biometeorol. 2011, 56, 1173-1177. [CrossRef]

20. Monahan, W.; Fisichelli, N. Climate exposure of US National Parks in a new era of change. PLoS ONE 2014, 9, e101302. [CrossRef]

21. Fisichelli, N.; Schuurman, G.; Monahan, W.; Ziesler, P. Protected area tourism in a changing climate: Will visitation at US National Parks warm up or overheat? PLoS ONE 2015, 10, e0128226. [CrossRef] [PubMed]

22. Hewer, M.; Scott, D.; Gough, W. Tourism Climatology for Camping: A Case Study of two Ontario Parks (Canada). Theor. Appl. Climatol. 2015, 121, 401-411. [CrossRef]

23. Hewer, M.; Scott, D.; Fenech, A. Seasonal Weather Sensitivity and the Implications of Climate Change for Park Visitation: A case study of Pinery Provincial Park (Ontario, Canada). Tour. Geogr. 2016, 18, 297-321. [CrossRef]

24. Hewer, M.; Scott, D.; Gough, W. Differences in the Importance of Weather and Weather-based Decisions among Campers in Ontario parks (Canada). Int. J. Biometeorol. 2017, 61, 1805-1818. [CrossRef] [PubMed]

25. Hewer, M.; Scott, D.; Gough, W. Differential Temperature Preferences and Thresholds among Summer Campers in Ontario's Southern Provincial Parks: A Canadian case study in tourism climatology. Theor. Appl. Climatol. 2018, 133, 1163-1173. [CrossRef]

26. Perry, A. Weather, climate and tourism. Weather 1972, 27, 199-203. [CrossRef]

27. Yapp, G.; McDonald, N. A recreation climate model. J. Environ. Manag. 1978, 7, 235-252.

28. Gössling, S.; Scott, D.; Hall, C.M.; Ceron, J.-P.; Dubois, G. Consumer behaviour and demand response of tourists to climate change. Ann. Tour. Res. 2012, 39, 36-58. [CrossRef]

29. Hewer, M.; Gough, W. Thirty years of assessing the impacts of climate change on outdoor recreation and tourism in Canada. Tour. Manag. Perspect. 2018, 26, 179-192. [CrossRef]

30. Vaidyanathan, A.; Kegler, S.; Saha, S.; Mulholland, J. A statistical framework to evaluate extreme weather definitions from a health perspective. Bull. Am. Meteorol. Soc. 2016, 97, 1817-1830. [CrossRef]

31. Cattiaux, J.; Ribes, A. Defining single extreme weather events in a climate perspective. Bull. Am. Meteorol. Soc. 2018, 99, 1557-1568. [CrossRef]

32. National Oceanic and Atmospheric Administration (NOAA). National Centers for Environmental Information (NCEI). 2019. Available online: https://www.ncdc.noaa.gov/climate-information/extreme-events (accessed on 20 December 2019). 
33. Hewer, M.; Gough, W. Using a multi-year temporal climate analogue approach to assess the impacts of projected climate change on seasonal park visitation in Ontario. Weather Clim. Soc. 2019, 11, $291-305$. [CrossRef]

34. Gough, W.; Rosanov, Y. Aspects of Toronto's climate: Heat island and lake breeze. Can. Meteorol. Oceanogr. Soc. Bull. 2001, 29, 67-71.

35. Mohsin, T.; Gough, W. Characterization and estimation of urban heat island at Toronto: Impact of the choice of rural sites. Theor. Appl. Climatol. 2012, 108, 105-117. [CrossRef]

36. Dwyer, J. Predicting daily use of urban forest recreation sites. Landsc. Urban Plan. 1988, 15, 127-138. [CrossRef]

37. Smith, K. The influence of weather and climate on recreation and tourism. Weather 1993, 48, 398-404. [CrossRef]

38. NOAA. SciJinks-Its All about Weather: Heatwaves. 2019. Available online: https://scijinks.gov/heat/ (accessed on 20 December 2019).

39. National Academy of Sciences. Global Warming is Contributing to Extreme Weather Events. 2019. Available online: https://sites.nationalacademies.org/BasedOnScience/climate-change-global-warming-iscontributing-to-extreme-weather-events/index.htm (accessed on 20 December 2019).

(C) 2020 by the author. Licensee MDPI, Basel, Switzerland. This article is an open access article distributed under the terms and conditions of the Creative Commons Attribution (CC BY) license (http://creativecommons.org/licenses/by/4.0/). 